\title{
Measurement of the Number of Photoelectrons per MeV for Neutron Detectors
}

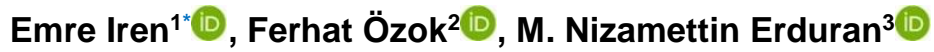 \\ ${ }^{1 *}$ Mimar Sinan Fine Arts University, Physics Department,Istanbul, Turkey.(e-mail: emre.iren@msgsu.edu.tr). \\ ${ }^{2}$ Mimar Sinan Fine Arts University, Physics Department,Istanbul, Turkey.(e-mail: ferhat.ozok@ msgsu.edu.tr). \\ ${ }^{3}$ Istanbul SabahattinZaim University, Faculty of Engineering And Natural Sciences Department of Computer Engineering,Istanbul, \\ Turkey. (nizamettin.erduran@izu.edu.tr).
}

\section{ARTICLE INFO}

Received: Jun., 11.2021

Revised: Jul., 02.2021

Accepted: Dec, 17.2021

\section{Keywords:}

Photomultiplier Tube

Single Photoelectron

Liquid Scintillator

Photoelectron Yield

Neutron Detection

Corresponding author:Emre Iren

ISSN:2536-5010 | e-ISSN: 2536-5134

\section{ABSTRACT}

The light gains of a detector system (photomultiplier tube and scintillator) is characterized by the number of photoelectrons produced per unit of energy (usually MeV). In this study, the results of light gain tests for 10 Hamamatsu R11833 model photomultiplier tubes are shown. Various radioactive sources were used in conjunction with the EJ309 liquid scintillator to determine the light gain. The number of photoelectrons produced per unit energy was determined by comparing the size of the signal generated by the photons produced by photomultiplier tube during the scintillation process using radioactive sources and the size of the signal generated when a single photoelectron was produced by the photomultiplier tube. The test results show that the performances of the photomultiplier tubes are sufficient for neutron detector arrays used in experiments with radioactive ion beams. The supply voltage of the photomultiplier tubes must be changed to achieve similar light gains.

\section{INTRODUCTION}

Neutrons by their nature do not interact with the electrons of atoms and do not cause ionization or excitation. Therefore, they cannot be measured directly. In order to detect neutrons, it is necessary to make them to interact with atomic nuclei. Proton recoils resulting from neutron interaction are measured with liquid scintillator based neutron detectors. These detectors are generally designed for use in experiments with radioactive ion beams. An example of this is the NEutron Detector Array (NEDA) project [1]. These detectors are also designed to work with radioactive beam generating systems under construction, such as SPIRAL2 at GANIL [2], SPES at LNL [3], ISOLDE at CERN [4] and FAIR at Darmstadt [5]. Neutron detector arrays consist of a large number of detectors covering a large solid angle of about $2 \pi$. It's also possible to use very large gamma ray detector arrays as an auxiliary detector system, such as AGATA [6], EXOGAM2 [7], GALILEO [8] and PARIS [9] spectrometers that use both with the test set up established in the Centre for Nuclear detectors and the Robotic Application and Research (NAR).

\section{EXPERIMENTAL SETUP}

To characterize photomultiplier tubes (PMTs), a 2"x2" cylindrical shaped liquid scintillator (EJ309) was used [10].
The light yield of EJ309 was about 12300 photons/MeV [11]. Since the PMTs's windows size are 5", the scintillator is solidly positioned in the center of the PMTs using a black plastic ring. The ring is made of plastic material with a 2" radius hole to hold the scintillator cell in the center of the PMT during each individual measurement. Before each measurement, the scintillator was attached to the PMT with a thin layer of silicone grease, and the system was placed in a housing prepared to seal off external light (Figure 1).

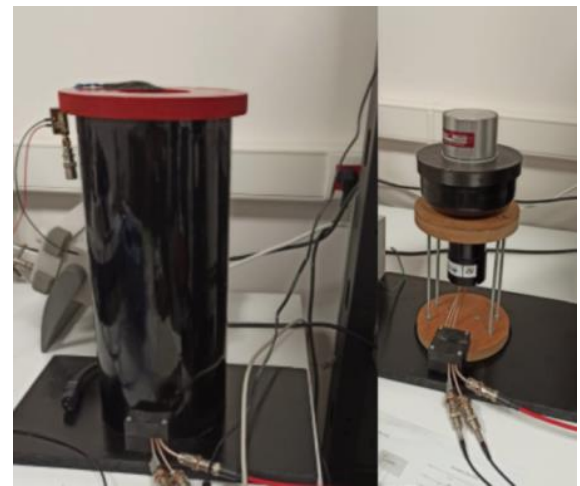

Figure 1. Neutron detector and housing designed using EJ309 liquid scintillator and Hamamatsu R11833 PMT 
Data acquisition systems combining both NIM and VME based devices were used. The schematically representation of the data acquisition system is shown in Figure 2.

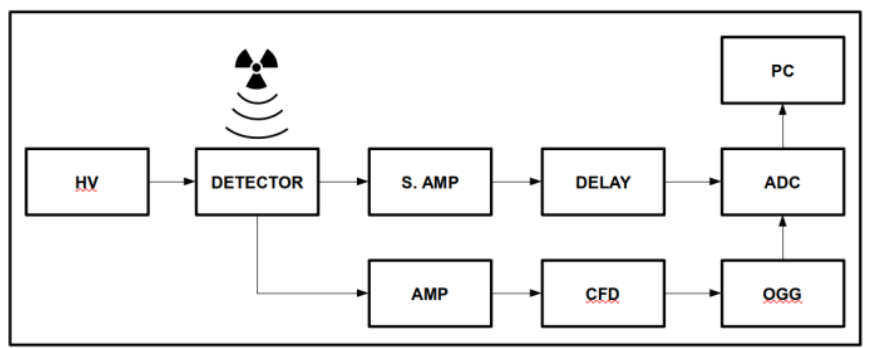

Figure 2. Schematic representation of the experimental setup

${ }^{137} \mathrm{Cs}$ and ${ }^{22} \mathrm{Na}$ radioactive sources were used in the measurements. The anode pulse output of the PMT was connected to a Shaping Amplifier (S.AMP) and then the signal shape was corrected and sent to the Analogue to Digital Converter (ADC) after a certain delay was applied. After the cathode output signal was first amplified via AMP, the gate signal was obtained using the Constant Fraction Discriminator (CFD) and the Octal Gate Generator (OGG) NIM modules and then this signal was sent to the ADC.

The supply voltage of PMTs has been determined between the negative $1100-1400 \mathrm{~V}$ range, considering the values used in the final test sheet provided by the manufacturer (Table 1).

TABLE 1

FINAL TEST SHEET SENT BY THE MANIFACTURER COMPANY (SUPPLY VOLTAGE IS $1250 \mathrm{~V}$ FOR ALL PMTS)

\begin{tabular}{ccccc}
\hline \hline PMT & $\begin{array}{c}\text { Cathode } \\
\text { Luminous } \\
\text { Sens. } \\
\mu \mathrm{A} / 1 \mathrm{~m}\end{array}$ & $\begin{array}{c}\text { Cathode } \\
\text { Luminous } \\
\text { Sens. } \\
\mu \mathrm{A} / 1 \mathrm{~m}\end{array}$ & $\begin{array}{c}\text { Anode } \\
\text { Dark } \\
\text { Current } \\
\text { nA }\end{array}$ & $\begin{array}{c}\text { Cathode } \\
\text { Blue } \\
\text { Sens. } \\
\text { Index }\end{array}$ \\
\hline CA0137 & 129.0 & 31.9 & 2.9 & 14.7 \\
CA0143 & 156.0 & 207.0 & 14.0 & 15.2 \\
CA0146 & 140.0 & 31.6 & 7.6 & 14.8 \\
CA0148 & 152.0 & 125.0 & 2.3 & 15.6 \\
CA0150 & 160.0 & 131.0 & 4.3 & 16.0 \\
CA0151 & 147.0 & 228.0 & 3.1 & 15.6 \\
CA0153 & 155.0 & 149.0 & 5.2 & 16.1 \\
CA0156 & 144.0 & 121.0 & 6.5 & 14.8 \\
CA0157 & 126.0 & 166.0 & 5.3 & 13.4 \\
CA0158 & 124.0 & 82.3 & 2.3 & 14.1 \\
\hline \hline
\end{tabular}

The signals digitized in the VME ADC module were sent to the PC and filled into histograms. The configuration information of the modules used in the experimental setup is shown in Table 2.

TABLE 2

CONFIGURATION OF THE MODULES USED IN THE EXPERIMENTAL SETUP SHOWN IN FIGURE 2 IN MEASUREMENTS MADE WITH SINGLE PHOTOELECTRON (SPE) AND RADIOACTIVE SOURCES FOR EACH PMT

\begin{tabular}{|c|c|c|c|c|c|c|c|}
\hline PMT & $\begin{array}{l}\text { Sour } \\
\text { ce }\end{array}$ & $\begin{array}{l}\text { HV } \\
\text { Value } \\
(\mathrm{V})\end{array}$ & $\begin{array}{l}\text { CFD } \\
\text { Thre } \\
\text { shold } \\
(\mathrm{mV})\end{array}$ & $\begin{array}{l}\text { AMP } \\
\text { Gain }\end{array}$ & $\begin{array}{l}\text { S. } \\
\text { AMP } \\
\text { Gain }\end{array}$ & $\begin{array}{l}\text { S. } \\
\text { AMP } \\
\text { S. } \\
\text { Time }\end{array}$ & $\begin{array}{l}\text { OGG } \\
\text { Wid } \\
\text { th }\end{array}$ \\
\hline \multirow{2}{*}{ CA0151 } & $\begin{array}{l}\mathrm{Na} \\
\mathrm{Cs}\end{array}$ & -1100 & -10 & $\mathrm{x} 30$ & $\times 5$ & $2 \mu \mathrm{s}$ & $6 \mu \mathrm{s}$ \\
\hline & SPE & -1100 & -10 & $\mathrm{x} 100$ & $\mathrm{x} 2 \mathrm{k}$ & $2 \mu \mathrm{s}$ & $6 \mu \mathrm{s}$ \\
\hline \multirow[t]{2}{*}{ CA0143 } & $\begin{array}{l}\mathrm{Na} \\
\mathrm{Cs}\end{array}$ & -1100 & -10 & $\mathrm{x} 30$ & $\mathrm{x} 5$ & $2 \mu \mathrm{s}$ & $6 \mu \mathrm{s}$ \\
\hline & SPE & -1100 & -10 & $\mathrm{x} 100$ & $\mathrm{x} 2 \mathrm{k}$ & $2 \mu \mathrm{s}$ & $6 \mu \mathrm{s}$ \\
\hline \multirow{2}{*}{ CA0150 } & $\begin{array}{l}\mathrm{Na} \\
\mathrm{Cs}\end{array}$ & -1100 & -10 & $\mathrm{x} 30$ & $\mathrm{x} 5$ & $2 \mu \mathrm{s}$ & $6 \mu \mathrm{s}$ \\
\hline & SPE & -1100 & -10 & $\mathrm{x} 100$ & $\mathrm{x} 2 \mathrm{k}$ & $2 \mu \mathrm{s}$ & $6 \mu \mathrm{s}$ \\
\hline CA0148 & $\begin{array}{l}\mathrm{Na} \\
\mathrm{Cs}\end{array}$ & -1100 & -10 & $\mathrm{x} 30$ & $x 5$ & $2 \mu \mathrm{s}$ & $6 \mu \mathrm{s}$ \\
\hline
\end{tabular}

\begin{tabular}{|c|c|c|c|c|c|c|c|}
\hline & SPE & -1100 & -10 & $\mathrm{x} 100$ & $\mathrm{x} 2 \mathrm{k}$ & $2 \mu \mathrm{s}$ & $6 \mu \mathrm{s}$ \\
\hline \multirow{2}{*}{ CA0157 } & $\begin{array}{l}\mathrm{Na} \\
\mathrm{Cs}\end{array}$ & -1100 & -10 & $\mathrm{x} 30$ & $\mathrm{x} 5$ & $2 \mu \mathrm{s}$ & $6 \mu \mathrm{s}$ \\
\hline & SPE & -1100 & -10 & $\mathrm{x} 100$ & $\mathrm{x} 2 \mathrm{k}$ & $2 \mu \mathrm{s}$ & $6 \mu \mathrm{s}$ \\
\hline \multirow[t]{2}{*}{ CA0153 } & $\begin{array}{l}\mathrm{Na} \\
\mathrm{Cs}\end{array}$ & -1100 & -10 & x30 & $\mathrm{x} 5$ & $2 \mu \mathrm{s}$ & $6 \mu \mathrm{s}$ \\
\hline & SPE & -1100 & -10 & $\mathrm{x} 100$ & $\mathrm{x} 2 \mathrm{k}$ & $2 \mu \mathrm{s}$ & $6 \mu \mathrm{s}$ \\
\hline \multirow{2}{*}{ CA0156 } & $\begin{array}{l}\mathrm{Na} \\
\mathrm{Cs}\end{array}$ & -1100 & -10 & x 30 & $\mathrm{x} 5$ & $2 \mu \mathrm{s}$ & $6 \mu \mathrm{s}$ \\
\hline & SPE & -1100 & -10 & $\mathrm{x} 100$ & $\mathrm{x} 2 \mathrm{k}$ & $2 \mu \mathrm{s}$ & $6 \mu \mathrm{s}$ \\
\hline \multirow{2}{*}{ CA0158 } & $\begin{array}{l}\mathrm{Na} \\
\mathrm{Cs}\end{array}$ & -1200 & -10 & $\mathrm{x} 30$ & $\mathrm{x} 5$ & $2 \mu \mathrm{s}$ & $6 \mu \mathrm{s}$ \\
\hline & SPE & -1200 & -10 & $\mathrm{x} 100$ & $\mathrm{x} 2 \mathrm{k}$ & $2 \mu \mathrm{s}$ & $6 \mu \mathrm{s}$ \\
\hline \multirow[t]{2}{*}{ CA0137 } & $\begin{array}{l}\mathrm{Na} \\
\mathrm{Cs}\end{array}$ & -1400 & -10 & $\mathrm{x} 30$ & $\mathrm{x} 5$ & $2 \mu \mathrm{s}$ & $6 \mu \mathrm{s}$ \\
\hline & SPE & -1400 & -10 & $\mathrm{x} 100$ & $\mathrm{x} 2 \mathrm{k}$ & $2 \mu \mathrm{s}$ & $6 \mu \mathrm{s}$ \\
\hline \multirow{2}{*}{ CA0146 } & $\begin{array}{l}\mathrm{Na} \\
\mathrm{Cs}\end{array}$ & -1400 & -10 & $\mathrm{x} 30$ & $\mathrm{x} 5$ & $2 \mu \mathrm{s}$ & $6 \mu \mathrm{s}$ \\
\hline & SPE & -1400 & -10 & $\mathrm{x} 100$ & $\mathrm{x} 2 \mathrm{k}$ & $2 \mu \mathrm{s}$ & $6 \mu \mathrm{s}$ \\
\hline
\end{tabular}

\section{MEASUREMENT}

The light yield of a detector system (PMT and scintillator) is usually characterized by the number of photoelectrons $\left(\mathrm{N}_{\text {phe }}\right)$ produced per unit energy (usually $\mathrm{MeV}$ ). $\mathrm{N}_{\text {phe }}$ is an important parameter that determines the performance of PMT. During the scintillation process, a $\gamma$-ray from a radioactive source interacts with the scintillator to create photons (usually in the visible lightspectrum). This value is around 12300 photons/MeV for the EJ309 liquid scintillator. These scintillation photons formed in the scintillator strike the photocathode on the PMT and eject electrons from photocathode. The ejected electrons are then multiplied at the dynodes in the PMT, creating an output signal of a certain amplitude and shape. If a single electron is ejected from the photocathode, the amplitude of the signal to be generated is lower. $\mathrm{N}_{\mathrm{phe}}$ is usually determined by comparing these two signal sizes.

When the $661.6 \mathrm{keV} \gamma$-rays emitted from ${ }^{137} \mathrm{Cs}$ radioactive source interact with the EJ309 liquid scintillator, it forms a Compton distribution with a Compton edge of $0.48 \mathrm{MeV}$ energy. Similarly, when the $511 \mathrm{keV}$ and $1274.5 \mathrm{keV} \gamma$-rays emitted from the ${ }^{22} \mathrm{Na}$ radioactive source interact with the EJ309 liquid scintillator, they form a Compton distribution with a Compton edge at $0.36 \mathrm{MeV}$ and $1.06 \mathrm{MeV}$, respectively. The energy of the Compton edge is used to measure $\mathrm{N}_{\text {phe }}$. The expression that gives the value of $\mathrm{N}_{\text {phe }}$ is as follows:

$$
N_{p h e}=\frac{P_{S P E}-P_{z O}}{P_{C . E .}-P_{z O}} \cdot \frac{G_{S P E}}{G_{S R C}} \cdot \frac{1}{E_{C . E .}}
$$

where $\mathrm{P}_{\text {C.E. }}$ and $\mathrm{P}_{\mathrm{SPE}}$ respectively are the positions of the Compton Edge peak and the single photoelectron peak. $\mathrm{P}_{\mathrm{z} 0}$ is the zero offset of the data acquisition system, $G_{S R C}$ and $G_{S P E}$ respectively are the gains of the amplifier used for the measurements with the source and single photoelectron. $\mathrm{E}_{\mathrm{C} . \mathrm{E}}$. is the Compton Edge energy [12-13].

\subsection{Determination of $P_{S P E}$}

The setup shown in Figure 2 was used to determine the single photoelectron spectrum. After applying the appropriate voltage value to each PMTs, the PMT's anode output signal was passed through S.AMP, the shaping time was adjusted to $2 \mu$ s and the unipolar output was connected to the ADC. The gain of the amplifier is set to the maximum level. This value 
will be used as the $\mathrm{G}_{\mathrm{SPE}}$ value in the calculation of $\mathrm{N}_{\text {phe. }}$. After making sure that there was no radioactive source around the detector, data collection was performed until a uniform spectrum was obtained (Figure 3). Here, a Gaussian fit is applied to the top of the SPE and the mean value (channel number) will be used as the $P_{S P E}$ value in calculating the $\mathrm{N}_{\text {phe }}$.

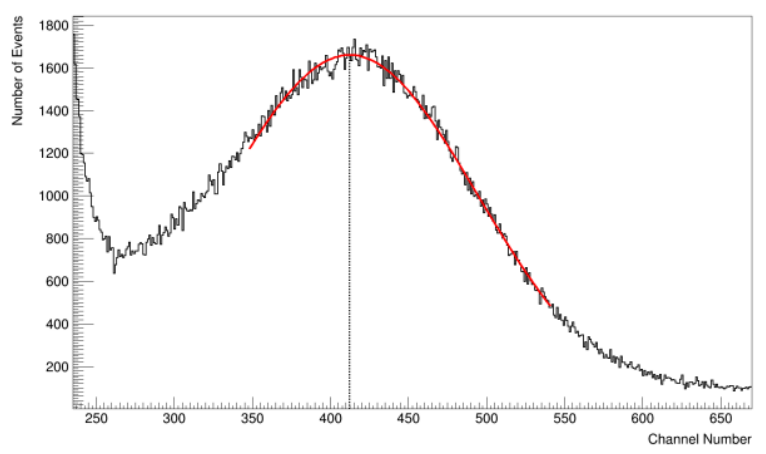

Figure 3. Single photoelectron spectrum obtained with the experimental setup

\subsection{Determination of $P_{C . E}$.}

The setup shown in Figure 2 was used to determine the Compton edge. After applying the appropriate voltage value to each PMT, the PMT's anode output signal was passed through S.AMP, the shaping time was adjusted to $2 \mu \mathrm{s}$ and the unipolar output was connected to the ADC. The gain of the amplifier was set to the minimum level. This value will be used as the $\mathrm{G}_{\text {SRC }}$ value in the calculation of $\mathrm{N}_{\text {phe }}{ }^{137} \mathrm{Cs}$ and ${ }^{22} \mathrm{Na}$ sources were placed over the separate semi-detector housing at a distance of $15 \mathrm{~cm}$ for ${ }^{22} \mathrm{Na}$ and $2 \mathrm{~cm}$ for ${ }^{137} \mathrm{Cs}$ and data collection was carried out until a uniform spectrum was obtained (Figure 4).
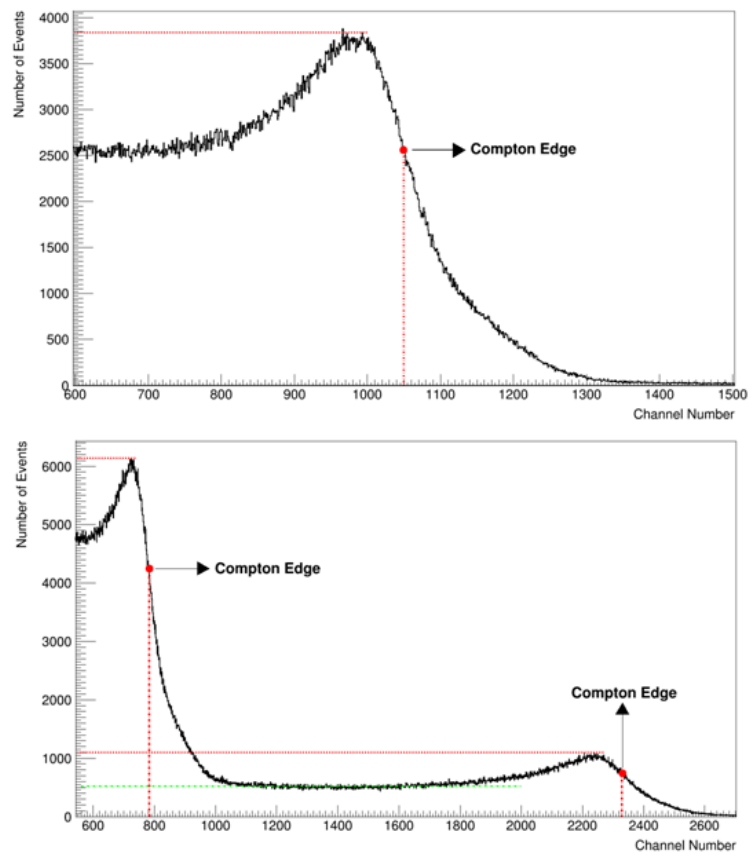

Figure 4. ${ }^{137} \mathrm{Cs}$ spectrum and (top) ${ }^{22} \mathrm{Na}$ spectrum (bottom) obtained with the experimental setup. The compton edges is indicated by a solid dot.

\subsection{Determination of $P_{z 0}$}

If there is no offset in the system, the $\mathrm{P}_{\mathrm{z} 0}$ value should be taken as 0 . However, in some cases DC offsets based on AMP or/and ADC may ocur [14]. In this case, if the necessary corrections are not made, the obtained $\mathrm{N}_{\text {phe }}$ values will be incorrect. In order to determine whether there is DC offset in the system energy calibration was performed with different radioactive sources with well-known values (Figure 5). The offset value was determined using energy calibration curve plotted in Figure 5. the offset value was determined. This value will be used as $P_{z 0}$ value in the calculation of $N_{\text {phe }}$.

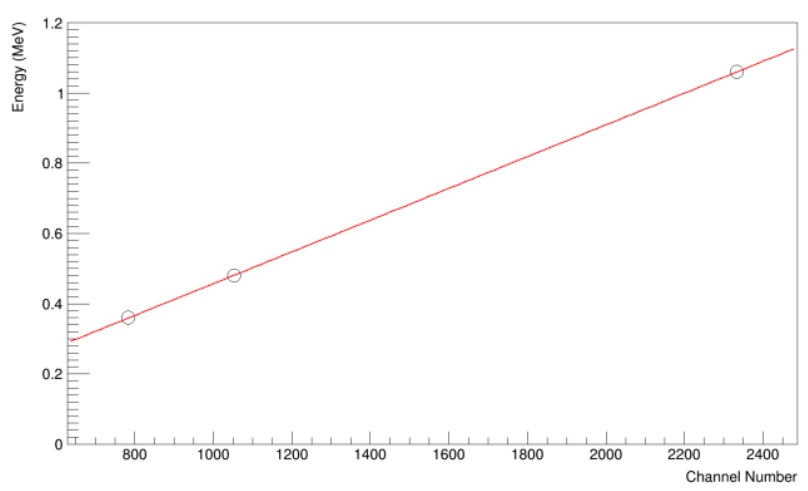

Figure 5. Energy calibration with different radioactive source

\section{RESULTS}

Measurement results of detector using EJ309 liquid scintillator and Hamamatsu R11833 model PMT are shown in

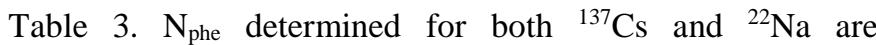
consistent with each other. The difference in $\mathrm{N}_{\text {phe }}$ obtained for each PMT is an expected result due to the structural differences of PMTs shown in Table 1.

TABLE 3

YIELD OF PHOTOELECTRONS $\left(\mathrm{N}_{\text {PHE }}\left[\mathrm{MEV}^{-1}\right]\right)$ FOR THE PMTS MEASURED WITH EJ309 LIQUID SCINTILLATORS IN THREE DIFFERENT ENERGY RANGES.

\begin{tabular}{cccc}
\hline PMT & & $\mathrm{N}_{\text {phe }}\left[\mathrm{MeV}^{-1}\right]$ & \\
\cline { 2 - 4 } & ${ }^{22} \mathrm{Na}$ & ${ }^{137} \mathrm{Cs}$ & $(1.06 \mathrm{MeV})$ \\
\hline CA0137 & 1792 & $(0.48 \mathrm{MeV})$ & 1781 \\
CA0143 & 1817 & 1770 & 1812 \\
CA0146 & 2009 & 1807 & 1997 \\
CA0148 & 1690 & 1985 & 1661 \\
CA0150 & 1846 & 1632 & 1831 \\
CA0151 & 2066 & 1815 & 2071 \\
CA0153 & 1836 & 2076 & 1810 \\
CA0156 & 2002 & 1782 & 1993 \\
CA0157 & 1697 & 1983 & 1681 \\
CA0158 & 1704 & 1664 & 1677 \\
\hline
\end{tabular}




\section{ACKNOWLEDGEMENT}

This study is supported by the Scientific and Technological Research Council of Turkey (TUBITAK Project No: 117F114).

\section{REFERENCES}

[1] ***, NEutron Detector Array (GANIL), http://pro.ganilspiral2.eu/spiral2/instrumentation/neda

[2] ***, SPIRAL2, http://pro.ganil-spiral2.eu/spiral2/what-isspiral2/description-of-spiral2

[3] ***, SPES, http://web.infn.it/spes/

[4] ***, ISOLDE(CERN), http://isolde.web.cern.ch/ISOLDE/

[5] ***, FAIR (Darmstadt), http://www.gsi.de/en/research/fair.htm

[6] ***, AGATA, http://www-w2k.gsi.de/agata/

[7] ***, EXOGAM2,

spiral2.eu/spiral2/instrumentation/exogam2

[8] ****,

http://pro.ganil-

http://www lnl infn it/ annrep/read_ar/2013/contributions/pdi 118_C113.pdf

[9] ***, PARIS, http://paris.ifj.edu.pl/index.php?lng=en

[10] ***, HamamatsuR11833 model Photomultiplier Tubes, https://www.hamamatsu.com/eu/en/product/type/R11833-10003/index.html

[11] ***, EJ309 liquid scintillator https://eljentechnology.com/products/liquid-scintillators/ej-301-ej-309

[12] Johan Nyberg, HOWTO measure the number of photoelectrons per $\mathrm{MeV}$ for the detectors of the Neutron Wall, https://nsg.physics.uu.se/sites/default/files/howto-nphe-v02.pdf

[13] D. Guarrera , G. Jaworski , B. Sayğ1 , PMTs of NEDA - Measurement of Photoelectrons Yield and Quantum Efficiency, http://www.Inl.infn.it/ annrep/read_ar/2016/contributions/pdfs/092_C_ 96_C091.pdf

[14] E. İnce and M. Türk, "COMPARATIVE STUDY OF 0.18MM LINEARIZED CMOS LOW NOISE AMPLIFIER", European Journal of Technique (EJT), c. 7, say1. 2, ss. 219-228, Ara. 2017

\section{BIOGRAPHIES}

Emre İREN Fatih, İstanbul, born in 1987. He received the B.S. in Physics from İstanbul University in 2012. He received the M.S. in Physics from Mimar Sinan Fine Arts University in 2017. From 2017 to 2019, he was a Teaching Assitant in İstanbul Arel University. Currently He is a PhD student in Mimar Sinan Fine Arts University Physics Department. Since 2019, he has been a Research Assistant with the Physics Department, Mimar Sinan Fine Art University.

Ferhat ÖZOK Kadiköy, İstanbul, born in 1979. He received the B.S. and M.S. degrees in Physics from the İstanbul University, in 2001,2004 respectively and the Ph.D. degree in Physics from İstanbul University, in 2011. From 2002 to 20011, he was a Research Assistant with the High Energy and Plasma Physics Department, Istanbul University. Since 2011, he has been an Assistant Professor with the Physics Department, Mimar Sinan Fine Arts University. His research interests include Instrumentation in Particle and Nuclear Physics, Detector R\&D and its applications.

M. Nizamettin ERDURAN Kadırga, Istanbul, born in 1951. He received the B.Sc. degree in physics in Istanbul University in 1975 and M.Sc. degree in the University of Edinburgh in physics and nuclear instrumentation in 1978, the $\mathrm{Ph} . \mathrm{D}$. degree in physics also from the University of Edinburgh, UK, in 1984. From 1985 to 1998 , he was a Researcher with the Cekmece Nuclear Research Centre, Physics Laboratory. From 1998 to 2010, he was professor of nuclear physics with the Istanbul University, he has been a Professor with the Computer Engineering Department, Istanbul Sabahattin Zaim University since 2011. He is the author of more than 50 articles. His research interests include fast neutron physics, nuclear structure physics and applied nuclear physics. 